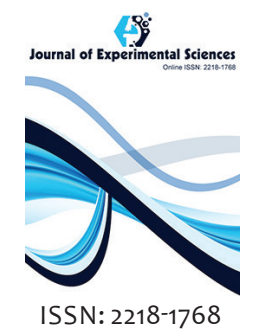

Received: April 18, 2018 Accepted: June 14, 2018 Published: June 18, 2018

*Corresponding Author: Abbas Lateef Abdurahman Email: agriman26@yahoo.com

\section{Correlation, regression and path analysis among yield and yield traits in Triticum dicoccum}

\author{
Maysoun M. Saleh', Dyab S. Moussa², Nader I. Alkaraki³ and \\ Abbas Lateef Abdurahman ${ }^{4,5 *}$
}

\begin{abstract}
${ }^{1}$ General Commission for Scientific Agricultural Research (GCSAR), Genetic Resources Department, Damascus, Syria, ${ }^{2}$ General Commission for Scientific Agricultural Research (GCSAR), Scientific Agricultural Research Center of Al-Ghab, Syria, ${ }^{3}$ General Commission for Scientific Agricultural Research (GCSAR), Izra Station, Scientific Agricultural Research Center of Dara, Syria, ${ }^{4}$ Faculty of Agriculture, University Putra Malaysia, 43400 UPM, Serdang, Selangor, Malaysia, 5 Iraqi Ministry of Agriculture, Iraq
\end{abstract}

\begin{abstract}
Seven wheat genotypes (Triticum dicoccum) and the local check sham5 were planted all at Al-Ghab and Izra Research centers in The General Commission for Scientific Agricultural Research in Syria during growing season 2010/2011. Yield components (number of total and fertile tillers per plant, number and weight of grains per spike, weight of thousand grain and individual plant grain yield) were studied in two sites in order to predict their effect and to determine their effects on grain yield in order to define selection criteria for grain yield. Results revealed all studied traits except total tillers number were positively correlated with grain yield, and only (fertile tillers number and grain number per spike and grain weight per spike) had a significant regression with grain yield and these traits can explain about (27.6, 67.7, 62.2)\% respectively of the variation final grain yield. Results of path analysis indicated that the direct effect of fertile tillers per plant and grain weight per spike on grain yield was positive and high $(0.6178,0.7563)$ respectively, so that we can depend on them in breeding program as selection criteria to increase grain yield in plant.
\end{abstract}

KEYWORDS: Triticum dicoccum, correlation, regression, path analysis

\section{INTRODUCTION}

In view of production and harvested area, wheat is major crop in the world and provides almost $20 \%$ of energy [1], wheat is widely cultivated in arid and semi-arid regions [2], about $65 \%$ of wheat production is used for humans and $17 \%$ as forages while $12 \%$ in industry [3]. Grain yield is a final product of combination of yield traits like grain number and grain weight per spike and fertile tillers number and thousand grain weight [4]. Correlation analysis can be a tool to have success in breeding programs [5] especially for yield traits [6] in order to increase the final grain weight [7]. Regression is used to define the importance of yield traits to be used as effective indexes to increase grain yield [8].

Path analysis enables us to partitioning of correlation into direct and indirect effects of different traits on grain yield $[9,10]$. Previous study [1] emphasis on any trait which has a positive direct effect on grain yield even if the correlation wasn't meaningful. Earlier work [11] found that fertile tillers number is one of the important traits which affect the final grain yield. Another research [12] reported that the increase grain weight per spike will eventually increase grain yield.
Some of the earlier works [13-15] emphasized role of fertile tillers on grain yield, and grain weight had a positive direct effect on grain yield. The present study was conducted to estimate the correlation between studied traits, and to predict their effect on grain yield through regression analysis, and to determine their direct and indirect effects on grain yield in order to define selection criteria for grain yield.

\section{MATERIAL AND METHODS}

Seven genotypes of primitive wheat Triticum dicoccum were planted in tow sites Al-Ghab research centre north of Damascus and Izra research station south of Damascus belongs to the General Commission of Scientific Agricultural research GCSAR in Syria during season 2010/2011 under rainfed conditions, in addition to local variety Sham 5 as control, the experiment was laid out in a Complete Randomized Block Design (RCBD) with three replications, each genotype was planted in plot which had six rows of one meter length and $25 \mathrm{~cm}$ space was left between rows while $5 \mathrm{~cm}$ space between plants, depth of planting was $3-5 \mathrm{~cm}$. All recommended cultural practices like irrigation and pesticide control were conducted according to

Copyright: (c) 2018 The authors. This article is open access and licensed under the terms of the Creative Commons Attribution License (http://creativecommons.org/licenses/by/4.0/) which permits unrestricted, use, distribution and reproduction in any medium, or format for any purpose, even commercially provided the work is properly cited. Attribution — You must give appropriate credit, provide a link to the license, and indicate if changes were made. 
Agricultural ministry guides. Following traits were studied from ten selected plants:

- Total tillers number per plant: Numbers of all tillers of each genotype were counted at maturity in each replication and average was computed.

- Fertile tillers number per plant: Numbers of fertile tillers of each genotype were counted at maturity in each replication and average was computed.

- Grain number per spike: The main spike was threshed manually and numbers of grains per spike were counted for each genotype.

- Grain weight per spike: Grain per spike was weighed using electric balance for each genotype in each replication.

- Thousand grain weight: 500 grains were counted randomly from each genotype and weighed on electric balance then adjusted to 1000 grain weight.

- Grain yield per plant: Average grain yield per plant was weighed using electric balance for each genotype in each replication.

Correlation between traits was studied using SPSS.15, and simple linear regression SLR was studied between grain yield per plant as the dependent variable and each of the following traits as independent variables (total tillers number per plant, fertile tiller number per plant, grain number per spike, grain weight per spike, thousand grain weight) using Genstat.12. Path coefficients analysis to define the direct and indirect effect of studied traits on grain yield was made according to [16] using Genstat.12, strength of direct and indirect effect value of the studied traits on grain yield was scaled according to [17] as follows: More than 1: very strong, $(0.3-0.9)$ : strong, $(0.2-0.29)$ : medium, $(0.1-0.19)$ weak, less than 0.1 is neglected.

\section{RESULTS AND DISCUSSION}

\section{Correlation}

Results of correlation study revealed a strong positive and highly significant correlation between grain yield per plant and each of fertile tillers number $\left(\mathrm{r}=0.541^{* * *}\right)$ and grain number $(\mathrm{r}=0.827)$, and grain weight $\left(\mathrm{r}=0.795^{* *}\right)$, and thousand grain weight $\left(r=0.432^{* *}\right)$. Total tillers number had a positive highly significant correlation with fertile tillers number $\left(\mathrm{r}=0.508^{* *{ }^{*}}\right)$ and negative significant correlation with thousand grain weight $(\mathrm{r}=-0.390 \%)$. Fertile tillers number had a positive significant correlation with grain number per spike $(r=0.362 *)$ and negative and highly significant correlation with thousand grain weight $\left(r=-0.396^{* *}\right)$. Correlation between grain number and grain weight was positive and highly significant $\left(\mathrm{r}=0.778^{*}\right)$, and the same relationship was between grain weight and thousand grain weight $\left(\mathrm{r}=0.776^{* *}\right)$ (Tablel).

Our data are in accordance with earlier results between grain yield and grain number per spike [18-22]. Other studies [23,24] also conducted similar results between grain yield and grain weight per spike. There are reports about the correlation between thousand grain weight and grain yield per plant [25]. Our results also agree with previous findings [26, 20, 27-31].

\section{Regression}

Results showed significant regression and each of fertile tillers per plant and grain number per spike and grain weight per spike as independent variables, while other traits like total tillers number and thousand grain weight hadn't any effect on grain yield as the regression wasn't meaningful (Table 2).

The adjusted coefficient of determination $\mathrm{R}^{2}$ between grain yield and each of fertile tillers number and grain number per spike and grain weight per spike was $(0.276,0.677,0.622)$ respectively which means that about $27.6 \%$ of variation in final grain yield could be explained by the variation in fertile tillers number represented by the nearest dots to the linear regression line in Figure. 1, and each of grain number per spike and grain weight per spike can explain $(67.7 \%, 62.2 \%)$ of final grain yield variation represented by the nearest dots to the linear regression line in Figure. 2. Simple linear regression equations were formed for the significant traits.

Where GY: grain Yield, FT: fertile tillers number, GN: grain number per spike, GW: grain weight per spike, (2.54, - 5.90, 1.83): are constants. (1.132) in equation 1: regression coefficient (b) between fertile tillers and grain yield revealed that increasing of one fertile tiller will cause an increasing in grain yield of 1.132. (0.4768) in equation 2: regression coefficient(b) between grain number and grain yield, means increasing only one grain will increase grain yield of 0.4768 . (7.930) in equation

Table 1: Correlation between studied traits

\begin{tabular}{lcccccc}
\hline & TT & FT & GN & GW & ThGW & GY \\
\hline TT & 1 & & & & & \\
FT & $0.508^{* *}$ & 1 & & & & \\
GN & 0.008 & $0.362^{*}$ & 1 & & & \\
GW & -0.252 & -0.046 & $0.778^{* *}$ & 1 & & \\
ThGW & $-0.390^{*}$ & $-0.396^{* *}$ & 0.226 & $0.776^{* *}$ & 1 & \\
GY & 0.079 & $0.541^{* *}$ & $0.827^{* *}$ & $0.795^{* *}$ & $0.432^{* *}$ & 1 \\
\hline
\end{tabular}

* significant at $0.05, * *$ significant at $0.01, \mathrm{TT}$ total tillers per plant, FT fertile tillers per plant, GN grain number per spike, GW grain weight per spike, ThGW thousand grain weight, GY grain yield per plant

Table 2: Summary of S.L.R. between grain yield and other traits

\begin{tabular}{|c|c|c|c|c|c|c|}
\hline Trait & Source & d.f. & Mean squares & $\mathrm{R}$ & $\mathrm{R}^{2}$ & Adjusted $\mathrm{R}^{2}$ \\
\hline \multirow[t]{3}{*}{$\mathrm{TT}$} & Regression & 1 & $12.30 \mathrm{~ns}$ & 0.079 & 0.006 & -0.019 \\
\hline & Residual & 40 & 49.93 & & & \\
\hline & Total & 41 & 49.01 & & & \\
\hline \multirow[t]{3}{*}{$\mathrm{FT}$} & Regression & 1 & $593.88 \mathrm{~s}$ & 0.541 ** & 0.293 & 0.276 \\
\hline & Residual & 40 & 35.39 & & & \\
\hline & Total & 41 & 49.01 & & & \\
\hline \multirow[t]{3}{*}{ GN } & Regression & 1 & $1375.85 \mathrm{~s}$ & $0.827 * *$ & 0.685 & 0.677 \\
\hline & Residual & 40 & 15.84 & & & \\
\hline & Total & 41 & 49.01 & & & \\
\hline \multirow[t]{3}{*}{ GW } & Regression & 1 & $1267.70 \mathrm{~s}$ & $0.795 * *$ & 0.632 & 0.622 \\
\hline & Residual & 40 & 18.54 & & & \\
\hline & Total & 41 & 49.01 & & & \\
\hline \multirow[t]{3}{*}{ ThGW } & Regression & 1 & $394.96 \mathrm{~ns}$ & $0.432 * *$ & 0.187 & 0.167 \\
\hline & Residual & 40 & 40.36 & & & \\
\hline & Total & 41 & 49.01 & & & \\
\hline
\end{tabular}


3: regression coefficient(b) between grain weight and grain yield, means that increasing one gram in grain weight will increase grain yield of 7.930. Our results are in agreement with previous studies [13,32-35].

\section{Path Analysis}

Results of path analysis indicated that the direct effect of grain weight per spike on grain yield was positive and high $(0.7563)$ while other indirect effects of grain weight positive or negative were all neglected which means that grain weight really effect the grain yield since the direct effect is almost equal to the correlation value. Direct effect of fertile tillers per plant on grain yield was high and positive (0.6178) while other indirect effects of fertile tillers were neglected but negative which minimize the total effect (correlation value) but it still high and positive $(0.5415)$, that means relation between fertile tillers and grain yield is effective. Direct effect of total tillers per plant was neglected and negative $(-0.0101)$ on grain yield, and also other indirect effects of total tillers via grain number and thousand grain weight were also negative and neglected, but the indirect effect of total tillers via fertile tillers was positive and high (0.3141) while negative and small $(-0.1908)$ via grain weight per spike, this result refers to the importance of the indirect effect of total tillers via fertile tillers on grain yield. Total effect of grain number was high and positive (0.8274) due combination of the indirect effect of grain number via grain weight which was positive and high (0.5885) and the indirect effect of grain number via fertile tillers which was positive and high(0.2235) because direct effect of grain number was negative and neglected, other indirect effects were all neglected. The indirect effect of thousand grain weight via grain weight per spike was high and positive $(0.5868)$ more than the positive and high total effect $(0.4324)$ which was lower due to the negative medium indirect effect of thousand grain weight via fertile tillers per plant (-0.2447), direct effect and other indirect effects were all neglected. combination of the indirect effect of grain number via grain weight which was positive and high (0.5885) and the indirect effect of grain number via fertile tillers which was positive and high $(0.2235)$ because direct effect of grain number was negative and neglected, other indirect effect were neglected (Table 3).

Where: TT total tillers per plant, FT fertile tillers per plant, GN grain number per spike, GW grain weight per spike, ThGW thousand grain weight, bold numbers are direct effect.

Our results are in agreement with $[36,37]$ whose results showed positive and high direct effect for grain weight per spike on grain yield per plant, and agree with [1] who found that the indirect effect of grain number via grain weight was positive and high on grain yield, and agree with results of [38] and [39] who resulted that the indirect effect of thousand grain weight via grain weight on grain yield was high and positive, and with [29] who referred to the high positive direct effect of fertile tillers on grain yield, and with [40] who found that the direct effect of grain number on grain yield was negative and neglected.

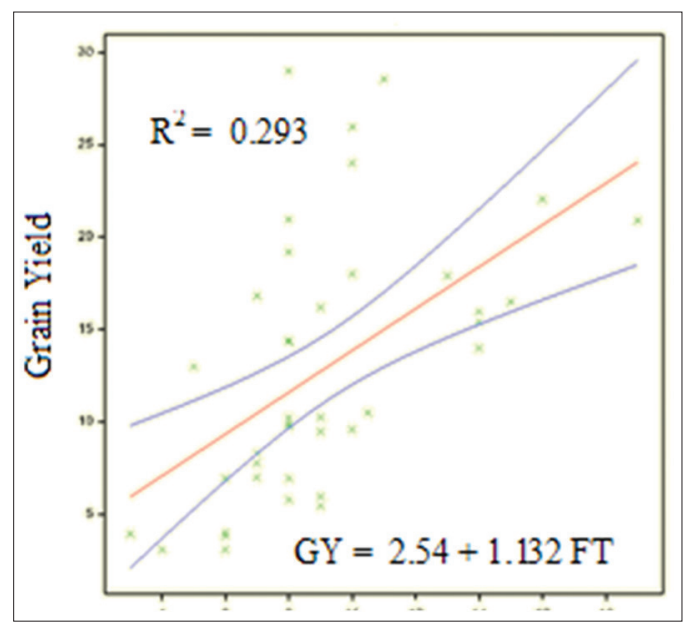

Figure 1: Effect of fertile tillers on grain yield

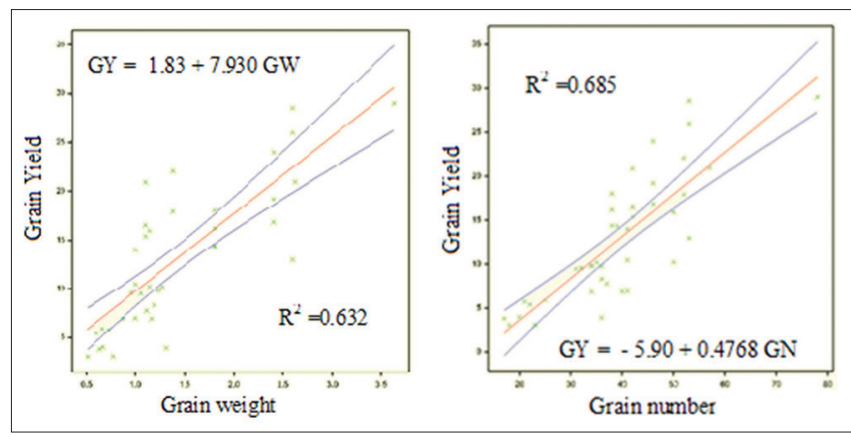

Figure 2: Effect of grain number and grain weight on grain yield

Table 3: Direct and in direct effect of studied traits on grain yield

\begin{tabular}{lllllll}
\hline & TT & FT & GN & GW & ThGW & R value \\
\hline TT & -0.0101 & 0.3141 & 0.0000 & -0.1908 & -0.0341 & 0.0790 \\
FT & -0.0051 & 0.6178 & -0.0015 & -0.0351 & -0.0346 & 0.5415 \\
GN & -0.0001 & 0.2235 & -0.0042 & 0.5885 & 0.0197 & 0.8274 \\
GW & 0.0026 & -0.0287 & -0.0032 & 0.7563 & 0.0678 & 0.7947 \\
ThGW & 0.0040 & -0.2447 & -0.0009 & 0.5868 & 0.0873 & 0.4324 \\
\hline
\end{tabular}

\section{CONCLUSION}

It was concluded from this study that correlation and regression analysis alone are not enough to determine the real relationship between studied traits and grain yield, but It was clear from the results of correlation and regression and path analysis the importance of fertile tillers per plant and grain weight per spike on the final grain yield per plant.

\section{RECOMMENDATION}

Wheat breeders must concentrate in breeding program on fertile tillers per plant and grain weight per spike as selection criteria to increase grain yield.

\section{AUTHOR CONTRIBUTIONS}

All authors had an equal contribution. 


\section{REFERENCES}

1. Nukasani V., N. R. Potdukhe, Bharad W., Deshmukh S., and S. M. Shinde. Genetic variability, correlation and path analysis in wheat. Journal of Wheat Research, 2013. 5(2): P.48-51.

2. Zarei L., K. Cheghamirza, E. Farshadfar. Interrelationships of some agronomic characters of durum wheat under supplementary irrigation at grain filling stage conditions. Agronomy and Plant Breeding Department, Razi University, Kermanshah, Iran, 2011.

3. FAO, Food and Agriculture Organization. Statistical yearbook. World Food and Agriculture, 2013

4. Tian J. C., Z. Y. Dend, R. B. Hu, and Y. X. Wang. Yield components of super wheat cultivars with different types and the path coefficient analysis on grain yield. Acta Agronica Sinica, 2012 (11): P. 1699-1705.

5. Afroz, R., M. S. H. Sharif., and L. Rahman. (2004). Genetic variability, correlation and path analysis in mustard and rape (Brassica spp.). Bangladesh. Journal of Plant Breeding and Genetics, 2004. 17(1): P.59-63.

6. Tariq M., Q. Ali, Khan A., G. A. Khan, B. Rashid, M. S. Rahi, A., I. A. Ali Nasir., and T. Husnain. Yield potential study of (Capsicum annuum L.) under the application of PGPR. Advanced Life Science, 2014. 1(4): P. 202-207.

7. Mahbub M. M., M. M. Rahman, M. S. Hossain, F. Mohamad, and M. M. Mir Kabir. Genetic variability, correlation and path analysis for yield and yield components in soybean, American-Eurasian Journal of Agriculture and Environment Science, 2015. 15 (2): P.231-236.

8. Farshadfar E. Multivariate principles and procedures of statistics. Taghbostan Pub. Kermanshah, Iran, 2004. P. 734.

9. Rahman, M. M., M. K. Bashar and M. G. Rasul. Molecular characterization and genetic variation in rice. LAP Lambert Academic Publishing GmbH and Co. KG, Saarbrucken, Germany, 2012: P. 1-45.

10. Honar N. R. Correlation between quantitative traits in rice yield through path analysis. Iranian Journal of Crop Science, 2003. 4(1): P. 35-25.

11. Mohamed S. G. A. S. M. G. Salama, and A. M. Abd El-Aziz. Statistical studies for evaluation some varieties of wheat. J. Agric. Sci., Mansoura Univ., 2005. P. 30 (6): 2969-2980.

12. Özberk I., H. Kiliç, F. Özberk, A. Atli, B. Karli, and Y. Coskun. Variety selection based on net return per hectare in durum wheat (Triticum durum L.). African Journal of Agricultural Research, 2011 6(4): P. 1016-1024.

13. Ashraf A., Abd El-Mohsen and M. A. Abd El-Shafi. Regression and path analysis in Egyptian bread wheat, Journal of Agriculture-Food and Applied Sciences, 20142 (5): P. 139-148.

14. Subhashchandra, B., H.C. Lohithaswa, S. A. Desai, R. R. Hanchinal, I. K. Kalappanavar, K. K. Math and P. M. Salimath. Assessment of genetic variability and relationship between genetic diversity and transgressive segregation in tetraploid wheat. Karnataka Journal of Agriculture Science, 2009 22(1): P. 36-38.

15. Mollasadeghi V., A. A. Imani, R. Shahryari and M. Khayatnezhad. Correlation and path analysis of morphological traits in different wheat genotypes under end drought stress condition. Middle-East Journal of Scientific Research, 2011 7(2): P. 221-224.

16. Singh, B. K., and B. D. Chudhary. Biometrical methods in quantitative genetic analysis. kalyani publishers. New Delhi, 1977

17. Lenka D. and B. Mishra. Path coefficient analysis of yield in rice varieties. Indian Journal of Agricultural Statistics, 1973 143: P. 376-379.

18. Mohammad S, M. Fida, and T. Mohammad. Path coefficient analysis in wheat. Sarhad Journal of Agriculture 18(4): P. 383-388.

19. Rajpoot P., O. Verma, and P Rajbahadur. Genetic variability, correlation and path coefficient analysis for yield and its contributing traits in wheat [Triticum aestivum (L.)]. International Journal of Science and Research (IJSR), 20134 (9).

20. Khan M. H., and A. N. Dar. Correlation and path coefficient analysis of some quantitative traits in wheat. African Crop Science Journal, 2010 18(1): P. 9-14.

21. Khokhar, M. I., Hussasn M., Zulkiffal M., Sabir W., Mahmood S. Jamil M.W., and J. Anwar. Studies on genetic variability and interrelationship among the different traits in wheat (Triticum aestivum L.). Krmiva, 2010 52(2): P.77-84.

22. Esmail, R.M. Correlation and path coefficient analysis of some quantitative traits with grain yield in bread wheat (Triticum aestivum L.).
Bulletin of the National Research Centre, Cairo, 2001 26(3): P. 395-408.

23. Heidari B., G. Saeidi, B. E. Sayed-Tabatabaei, and K. Suenaga. Interrelationships of agronomic characters in a doubled haploid population of wheat, Czech Journal of Genetics and Plant Breeding 2005 41: P. 233-237

24. Moucheshi A. S., M. Pessarakli, and B. Heidari. Comparing relationships among yield and its related traits in mycorrhizal and nonmycorrhizal inoculated wheat cultivars under different water regimes using multivariate statistics, International Journal of Agronomy, 2013 1: P. 1-14.

25. Mondal, S.K. and M.R. Khajuria. Correlation and path analysis in bread wheat (Triticum aestivum L.) under rainfed condition. Environment and Ecology, 2001 18(2): P. 405-408.

26. Saleh, S. H. Performance, correlation and path coefficient analysis for grain yield and its related traits in diallel crosses of bread wheat under normal irrigation and drought conditions. World Journal of Agricultural Sciences, 2011 7(3): P. 270-279.

27. Siahpoosh, M. S., Y. Emam., and A. Saidi. Genotypic variation, heritability, genotypic and phenotypic correlation coefficients of grain yield, its components and some morpho-physiological characters in bread wheat (Triticum aestivum L.). Iranian Journal of Crop Sciences, 20035 (2): P. 474.

28. Ali I. H., and E. F. Shakor. Heritability, variability, genetic correlation and path analysis for quantitative traits in durum and bread wheat under dry farming conditions. Mesoptamia J. Agri., 2012. 40 (4): P. 27-39.

29. Khan A. A., M. A. Alam, M. K. Alam, M. J. Alam, and Z. I. Sarker. Genotypic and phenotypic correlation and path analysis in durum wheat (Triticum turgidum I. var. durum), Bangladesh Journal of Agriculture Research, 2013 38(2): P. 219-225.

30. Karimizadeh R., P. Sharifi, and M. Mohammadi. Correlation and path coefficient analysis of grain yield and yield components in durum wheat under two irrigation and rain fed condition. International Journal of Agriculture Research and Review, 20122 (3):P. 277-283.

31. Dogan R. (2009). Correlation and path coefficient analysis for yield and some yield components of durum wheat (triticum turgidum var durum I.) in West Anatolia Conditions. Pakistan Journal of Botany, 2009 41(3): P.1081-1089.

32. Olgun M. and C. Aygün. Evaluation of yield and yield components by different statistical methods in wheat (T. aestivum L.), Ph.D thesis, Falculty of Agriculture. Department of Field Crops. Eskisehir. Turkey, 2011.

33. Majumder D. A. N. A. K. M. Shamsuddin, M. A. Kabir and L. Hassan Genetic variability, correlated response and path analysis of yield and yield contributing traits of spring wheat. Journal of Bangladesh Agriculture University, 20086 (2): P. 227-234.

34. Maas EV, S. M. Lesch, L. E. Francois, and C. M. Grieve (1996). Contribution of individual culms to yield of salt-stressed wheat. Crop Science, 1996 36: P. 142-149.

35. Efyoni D, and M Mahloji. Correlation analysis of some agronomic traits in wheat (Triticum aestivum L.) genotypes under salinity stress. Journal of Seed Plant, 2005 22: P. 186-199.

36. Sharma V., I. S. Pawar, and R. Munjal. Variability parameters, correlation and path coefficients for yield, its components and quality traits in bread wheat. National Journal of Plant Improvement, 2006 8(2): P. 153-155.

37. Singh N., Singh T., and N. Kumar. Genetic variability and correlation analysis over different environments in bread wheat (T. aestivum L.). Plant Achieves, 2009 9(2): P. 685-688

38. Ata A., B. Yousaf, Khan A S., Subhani G M., Asadullah H. M., and A. Yousaf. Correlation and path coefficient analysis for important plant attributes of spring wheat under normal and drought stress conditions. Journal of Biology, Agriculture and Healthcare, 20144 (8): P. 66-73.

39. Aycicek, M. and T. Yildirim. Heritability of yield and some yield components in bread wheat (Triticum aestivum I.) genotypes. Bangladesh Journal of Botany, 2006 35(1): P. 17-22.

40. Gelalcha and R. R. Hanchinal. Correlation and path analysis in yield and yield components in spring bread wheat (Triticum aestivum L.) genotypes under irrigated condition in Southern India. African Journal of Agricultural Research, 2013 8(24): P. 3186-3192. 